\title{
Jasmonic and salicylic acid-induced resistance in sorghum against the stem borer Chilo partellus
}

\author{
Barkat Hussain • Abdul Rashid War • Hari Chand Sharma
}

Received: 5 February 2013 / Accepted: 12 August 2013 /Published online: 24 August 2013

(C) Springer Science+Business Media Dordrecht 2013

\begin{abstract}
Induced resistance was studied in three sorghum genotypes (IS2205, ICSV1 and ICSV700) against Chilo partellus (Swinhoe) (Lepidoptera; Pyralidae) infestation and jasmonic acid (JA) and salicylic acid (SA) application. The activity of plant defensive enzymes [peroxidase (POD), polyphenol oxidase (PPO), superoxide dismutase (SOD), and catalase (CAT)], and the amounts of total phenols, hydrogen peroxide $\left(\mathrm{H}_{2} \mathrm{O}_{2}\right)$, malondialdehyde (MDA), and proteins were recorded at 6 days after infestation. The induction of enzyme activities and the amounts of secondary metabolites varied among the genotypes and treatments. The genotype IS2205 showed a stronger effect than that of ICSV1 or ICSV 700. Treatment with JA followed by insect infestation induced greater levels of enzymes and secondary metabolites. The results suggest that JA induces greater levels of resistance components in sorghum plants against insect pests. Thus, pretreatment of plants with elicitors including JA and SA could provide a greater opportunity for plant defense against herbivores.
\end{abstract}

\footnotetext{
B. Hussain

Division of Entomology, Sheri-Kashmir University of Agricultural Sciences and Technology-K (SKUAST-K), Shalimar 190 006, India

B. Hussain $(\bowtie) \cdot$ A. R. War $\cdot$ H. C. Sharma International Crops Research Institute for the Semi-Arid Tropics (ICRISAT),

Patancheru, Andhra Pradesh 502 324, India

e-mail: bhatbari@rediffmail.com
}

Keywords Antioxidant enzymes · Biotic stress · Induced resistance $\cdot$ Phytohormones $\cdot$ Poaceae . Sorghum bicolor

\section{Introduction}

Herbivorous insects use diverse feeding strategies to obtain nutrients from their host plants. Rather than acting as passive victims in these interactions, plants respond to herbivory with the production of toxins and defensive proteins that target physiological processes in the insect (Kawazu et al. 2012; Zhao et al. 2009). This highly dynamic form of immunity is initiated by the recognition of insect oral secretions and signals from injured plant cells. Plants have developed a wide array of defense strategies against insect herbivory, which could be constitutive and/or induced (He et al. 2011; Scott et al. 2010; War et al. 2012). The constitutive resistance is always present in plants irrespective of the external stimuli, whereas the induced resistance occurs in response to the external stimuli. These initial cues are transmitted within the plant by signal transduction pathways that include calcium ion fluxes, phosphorylation cascades and, in particular, the jasmonate pathway (He et al. 2011; Scott et al. 2010; Shivaji et al. 2010; Walling 2000). The jasmonic acid pathway plays a central and conserved role in promoting resistance to a broad spectrum of insects (Shivaji et al. 2010; Walling 2000). Although constitutive resistance is the first and primary defense against insects, induced resistance is more reliable and effective. It 
reduces the reallocations costs as it is produced when in demand. This induced defense against insect herbivory can be direct or indirect. Indirect induced defenses attract natural enemies of herbivores, whereas direct induced defenses directly affect the performance and preference of the attacking herbivore (Arimura et al. 2009; Heng-Moss et al. 2004; Scott et al. 2010). Chemical defense strategies involve secondary metabolites and proteins which may be present constitutively or induced by challenges such as herbivore wounding (Heng-Moss et al. 2004; War et al. 2011a, 2012). Direct and indirect defense mechanisms can function additively against the herbivore. Phytohormones are involved in plant defense against insect herbivores. These mediate plant signaling pathways, which lead to the production of various defensive secondary metabolites and proteins. The important phytohormones that play active roles in plant defense against various stresses are jasmonic acid (JA) and salicylic acid (SA) (Kawazu et al. 2012; Shivaji et al. 2010; War et al. 2011b; Zhao et al. 2009).

The important oxidative enzymes induced in plants in response to insect herbivory include peroxidases (POD), polyphenol oxidase (PPO), superoxide dismutase (SOD), phenylalanine ammonia lyase (PAL), lipoxygenase (LOX), catalase (CAT) and ascorbate peroxidase (APX) (Scott et al. 2010; War et al. 2012; Zhao et al. 2009). POD is an important antioxidative enzyme involved in plant defense against insect herbivory (He et al. 2011). It produces semiquinone free radicals and subsequently the quinines, which are highly toxic to insect pests (Barbehenn et al. 2010). The PPO is an antinutritional enzyme, and reduces the food quality of the plant tissues due to the oxidation of phenols to highly reactive and toxic quinines (Bhonwong et al. 2009; War et al. 2012). The SOD is an important antioxidative enzyme in plants involved in the conversion of toxic, highly reactive and unstable free radicals into less toxic and relatively stable $\mathrm{H}_{2} \mathrm{O}_{2}$ (Raychaudhuri \& Deng 2000). CAT is an important enzyme in reactive oxygen species (ROS) scavenging systems (Heidari 2009; Khattab \& Khattab 2005). Oxidation of phenols results in the production of toxic quinones that affect the insect growth and development, while some phenols are directly toxic to insect pests (Howe \& Jander 2008; War et al. 2013). $\mathrm{H}_{2} \mathrm{O}_{2}$ is an important stable ROS involved in plant defense against insect herbivory. It acts as a second messenger in signal transduction pathways, which lead to the production of toxic chemicals (Maffei et al. 2007). Malondialdehyde (MDA) is an important indicator of plant defense against insect pests (Gechev et al. 2002).

Sorghum (Sorghum bicolor Moench) is an essential food and cash crop for millions of people in Africa, Asia, USA, Australia and Latin America and is the fifth major cereal after wheat, rice, maize and barley. Chilo partellus (Swinhoe) is the most serious pest of sorghum and maize in Asia and Africa (Sharma et al. 2003). It is difficult to control, largely because of the cryptic and nocturnal habits of the adult moths. In addition, due to the protection provided to the immature stages by the stem of the host plant, the insecticidal film sprayed on the crop does not reach to the target organism. The losses caused by this insect are to the tune of US\$ 300 million annually (ICRISAT 1992). It can potentially damage all the above ground parts of the plant from the second fortnight after seedling emergence until harvest of the crop. Young larvae feeding results in pinholes and is followed by elongated lesions on the leaf whorls. When the pest attacks at an early stage it destroys the growing point commonly known as "dead heart" due to drying of two to three central leaves - thus reducing plant vigor and photosynthetic efficiency, delaying flowering and ultimately leading to the reduction in grain yield. The older larvae descend down inside the whorl leaves, bore inside the stem and cause stem tunneling that disrupts the nutrient supply to the above canopy, which leads to the chaffy panicles and ultimately to reduction in fodder quality and yield. The present studies were carried out to understand the induced resistance in sorghum genotypes against $C$. partellus by exogenous application of JA and SA. The studies were focused on various antioxidative enzymes and secondary metabolites involved in plant resistance against insect pests.

\section{Materials and methods}

Chemicals Ethylene diamine tetra acetic acid (EDTA), bovine serum albumin (BSA), guaiacol, polyvinylpyrrolidone (PVP), proline, glucose, jasmonic acid, salicylic acid, tannic acid, dithiothretol (DTT), disodium hydrogen phosphate, sodium dihydrogen phosphate, nitro-blue tetrazolium salt (NBT), methionine, L-phenylalanine, potassium iodide $(\mathrm{KI})$, and sodium carbonate $\left(\mathrm{Na}_{2} \mathrm{CO}_{3}\right)$ were obtained from Sigma Aldrich, USA. Catechol was obtained from Glaxo Laboratories, Mumbai, India. Glycine and trichloroacetic acid (TCA) were obtained 
from Sisco Research Lab., Mumbai, India. 2mercaptoethanol, gallic acid and Folin-Ciocalteu reagent were obtained from Merck, Mumbai, India. Thiobarbituric acid (TBA) was obtained from HiMedia Pvt. Ltd., Mumbai, India. Ammonium sulphate was obtained from Qualigens Fine Chemicals, Mumbai, India. The chemicals used in this study were of analytical grade.

The spectrophotometer used for the estimation of biochemical parameters was Hitachi UV - 2900 (Hitachi, Japan).

Insects The insects used for the studies were obtained from a well maintained insect rearing laboratory at International Crops for Semi-Arid Tropics (ICRISAT), Patancheru, Andhra Pradesh, India and culture of $C$. partellus was maintained under controlled conditions, 16h:8h L:D regime at $25 \pm 1^{\circ} \mathrm{C}$ and $65 \pm$ $5 \%$ r.h. on a sorghum-based artificial diet (Taneja \& Leuschner 1985). Aqueous sugar solution $10 \%$ was offered as food to the adults. The pupae were washed with $2 \%$ sodium hypochlorite solution and transferred to plastic jars containing vermiculite. Adults were transferred to iron oviposition cages $(30 \times 30 \times 30$ $\mathrm{cm}$ ), and provided with butter paper for oviposition.

Sorghum plants (Sorghum bicolor (L.) Moench) Seeds of sorghum genotypes (IS2205, ICS1 and ICSV700) were sown in plastic pots measuring $30 \times 30 \mathrm{~cm}$ diam in a greenhouse (temp. $27 \pm 3^{\circ} \mathrm{C}, 65 \pm 5 \%$ r.h.) to study the effect of two signaling molecules (JA and SA) on induced resistance to C. partellus. A few days after germination, only three plants were allowed to grow in each plastic pot to provide a uniform plant stand for all the test genotypes. At stage V2 (five-leaf stage), plants were sprayed with JA $(1 \mathrm{mM})$ and SA $(1 \mathrm{mM})$, then infested with $C$. partellus (JA $+\mathrm{IN}$ and $\mathrm{SA}+\mathrm{IN}$, respectively) and another treatment was infested with $3^{\text {rd }}$ instar larvae of $C$. partellus (IN); a separate unsprayed and uninfested control (UT) was set for all the genotypes. Before releasing the $3^{\text {rd }}$ instar larvae, plants were enclosed in plastic jars to avoid the movement of larvae from one plant to another plant. After 6 days of infestation, leaves were excised and collected from the infested and uninfested control plants to study the activity of various defensive enzymes including POD, PPO, and CAT, and the amounts of secondary metabolites such as phenols, tannins, and of $\mathrm{H}_{2} \mathrm{O}_{2}$, MDA and proteins.
Enzyme extraction Fresh leaves $(0.5 \mathrm{~g})$ were ground in $3 \mathrm{ml}$ of ice cold $0.1 \mathrm{M}$ Tris-HCl buffer ( $\mathrm{pH}$ 7.5) containing $5 \mathrm{mM}$ 2-mercaptoethanol, 1\% polyvinylpyrrolidone (PVP), $1 \mathrm{mM}$ DTT, and $0.5 \mathrm{mM}$ EDTA. The homogenate was centrifuged at $16,000 \times g$ for $20 \mathrm{~min}$ and the supernatant was collected.

Peroxidase (POD) assay Peroxidase activity was estimated according to the method of Shannon et al. (1966) with slight modification. The reaction mixture $(2.9 \mathrm{ml})$ containing $0.1 \mathrm{M}$ sodium phosphate buffer ( $\mathrm{pH} 6.5$ ), $0.8 \mathrm{mM} \mathrm{H}_{2} \mathrm{O}_{2}$ and $5 \mathrm{mM}$ guaiacol was taken in a test tube, to which $0.1 \mathrm{ml}$ of enzyme source was added and the absorbance was read at $470 \mathrm{~nm}$ for $2 \mathrm{~min}$ at 15 -sec intervals. Enzyme activity was expressed as $\Delta \mathrm{OD} \mathrm{min}^{-1}$.

Polyphenol oxidase (PPO) assay Polyphenol oxidase activity was estimated according to the method of Mayer \& Harel (1979) with some modifications. To $2.9 \mathrm{ml}$ of $0.1 \mathrm{M}$ sodium phosphate buffer $(\mathrm{pH} 6.8)$, $0.1 \mathrm{ml}$ of enzyme source and $0.1 \mathrm{ml}$ of substrate ( $0.05 \mathrm{M}$ catechol) were added. Absorbance was read at $420 \mathrm{~nm}$ for $3 \mathrm{~min}$ at $30-\mathrm{sec}$ intervals. Enzyme activ-

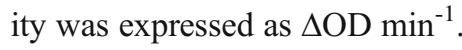

Superoxide dismutase (SOD) assay The activity of SOD was assayed by the method of Beauchamp \& Fridovich (1971) with slight modifications. $3 \mathrm{ml}$ of $0.05 \mathrm{M}$ sodium phosphate buffer with $0.1 \% \mathrm{NaCl}(\mathrm{pH}$ 7.8) was taken in a test tube to which $0.3 \mathrm{ml}$ of $0.1 \mathrm{mM}$ EDTA, $0.3 \mathrm{ml}$ of $0.13 \mathrm{mM}$ methionine, $0.1 \mathrm{ml}$ of $0.02 \mathrm{mM}$ $\mathrm{KCN}, 0.3 \mathrm{ml}$ of $0.75 \mathrm{mM}$ NBT, $0.3 \mathrm{ml}$ of $0.02 \mathrm{mM}$ riboflavin and $0.1 \mathrm{ml}$ of enzyme extract were added. The reaction mixture was illuminated in glass test tubes by two sets of Philips $40 \mathrm{~W}$ fluorescent tubes for $1 \mathrm{~h}$. Identical solutions that were kept in the dark served as blanks. Absorbance was read at $560 \mathrm{~nm}$ against the blank and the activity was expressed as $\Delta \mathrm{OD} \mathrm{min}^{-1}$.

Catalase (CAT) Catalase activity was assayed as described by Zhang et al. (2008). The reaction mixture consisted of $1 \mathrm{ml}$ of Tris-HCl buffer (pH 7.0), $0.1 \mathrm{ml}$ of partially purified enzyme extract and $0.2 \mathrm{ml}$ of $\mathrm{H}_{2} \mathrm{O}_{2}$. Absorbance was read at $240 \mathrm{~nm}$ for $2 \mathrm{~min}$ and the enzyme activity was expressed as units $\mathrm{mg}^{-1}$ protein.

Phenolic content Leaves $(0.5 \mathrm{~g})$ were homogenized in $3 \mathrm{ml}$ of $80 \%$ methanol and agitated for $15 \mathrm{~min}$ at $70^{\circ} \mathrm{C}$. The homogenate was centrifuged at $10,000 \mathrm{rpm}$ for 
10 min and the supernatant was collected, which was used for the estimation of total phenols by the method of Zieslin \& Ben-Zaken (1993) with some modifications. To $2 \mathrm{ml}$ of $2 \%$ sodium carbonate $\left(\mathrm{Na}_{2} \mathrm{CO}_{3}\right)$ taken in a test tube, $1 \mathrm{ml}$ of methanol extract was added. The solution was incubated for $5 \mathrm{~min}$ at room temperature and $0.1 \mathrm{ml}$ of $1 \mathrm{~N}$ Folin-Ciocalteu reagent was added. The solution was re-incubated for $10 \mathrm{~min}$ and absorbance of the blue color was measured at $760 \mathrm{~nm}$. Phenolic concentration was expressed as mg catechol equivalents $\mathrm{g}^{-1} \mathrm{FW}$ (mg GAE $\mathrm{g}^{-1} \mathrm{FW}$ ).

Hydrogen peroxide (H2O2) content Hydrogen peroxide content was estimated by the method of Noreen \& Ashraf (2009). Fresh leaf tissue (0.1 g) was homogenized in $2 \mathrm{ml}$ of $0.1 \%(\mathrm{w} / \mathrm{v})$ trichloroacetic acid (TCA) in pestle and mortar and centrifuged at $12,000 \times \mathrm{g}$ for $15 \mathrm{~min}$. To the supernatant $(0.5 \mathrm{ml})$, $0.5 \mathrm{ml}$ of phosphate buffer $(\mathrm{pH} \mathrm{7.0)}$ and $1 \mathrm{ml}$ of $1 \mathrm{M}$ potassium iodide (KI) were added. The absorbance was read at $390 \mathrm{~nm}$. $\mathrm{H}_{2} \mathrm{O}_{2}$ concentration was expressed as $\mu \mathrm{mol} \mathrm{g}{ }^{-1} \mathrm{FW}$ (extinction coefficient of $\mathrm{H}_{2} \mathrm{O}_{2} 0.28 \mu \mathrm{M} \mathrm{cm}^{-1}$ ).

Malondialdehyde (MDA) content MDA content was determined by the method of Carmak \& Horst (1991) with minor modification. Fresh leaf tissue $(0.2 \mathrm{~g})$ was homogenized in $3 \mathrm{ml} \mathrm{0.1 \% (w/v)} \mathrm{trichloroacetic} \mathrm{acid}$ (TCA) at $4^{\circ} \mathrm{C}$, centrifuged at $20,000 \times g$ for $15 \mathrm{~min}$. To

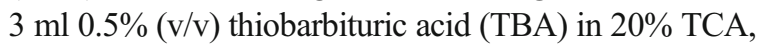
$0.5 \mathrm{ml}$ of supernatant was added. The mixture was incubated at $95^{\circ} \mathrm{C}$ in a shaking water bath for $50 \mathrm{~min}$ and the reaction was stopped by cooling the tubes in an ice water bath. Then samples were centrifuged at $10,000 \times g$ for $10 \mathrm{~min}$ and the absorbance of the supernatant was read at $532 \mathrm{~nm}$. The value for nonspecific absorption at $600 \mathrm{~nm}$ was subtracted. The concentration of TBARS was calculated using the absorption coefficient $155 \mathrm{mmol}^{-1} \mathrm{~cm}^{-1}$ and expressed as nanomol $\mathrm{g}^{-1} \mathrm{FW}$.

Protein content Protein content was determined by the method of Lowry et al. (1951) using bovine serum albumin as standard.

Statistical analysis The data were analyzed by analysis of variance (ANOVA) using SPSS (Ver. 11.5). Tukey's HSD test was applied to separate the means.

\section{RESULTS}

POD activity Across the treatments within the genotypes, JA-treated plants showed significantly greater POD activity compared with the plants treated with SA, infested and untreated control plants in IS2205 and ICSV700 (Fig. 1). No significant difference was observed in ICSV1 across the treatments. Among the genotypes, IS2205 plants showed significantly higher POD activity in all the treatments as compared with the corresponding treatments of ICSV1 and ICSV700.

PPO activity The JA + IN treated plants in IS2205 and ICSV1 showed significantly greater PPO activity as compared with the SA + IN treated, IN, and untreated control plants (Fig. 2). However, in ICSV700, JA + IN and SA + IN treated plants showed significantly higher PPO activity than those of insect-infested and untreated plants. Across the genotypes, IS2205 and ICSV1 showed significantly higher PPO activity in all the treatments as compared with that of the ICSV700.

SOD activity The SOD activity of sorghum genotypes increased in various treatments (Fig. 3). Among the treatments, JA + IN treated plants showed significantly greater SOD activity compared with the plants treated with $\mathrm{SA}+\mathrm{IN}$, IN, and untreated control plants in all the tested genotypes. Across the genotypes, no significant difference as observed in SOD activity in JA + IN

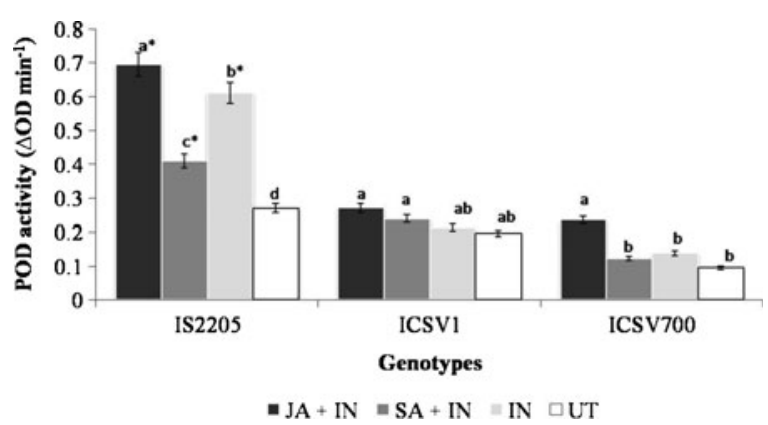

Fig. 1 Peroxidase (POD) activity $\left(\triangle \mathrm{OD} \mathrm{min}^{-1}\right)$ of sorghum genotypes after Chilo partellus infestation and jasmonic acid (JA) and salicylic acid (SA) application. Within a genotype, bars (mean $\pm \mathrm{SD}$ ) of the same color with a common letter do not differ statistically at $P \leq 0.05$. JA $+\mathrm{IN}=$ treatment with $\mathrm{JA}$ and infested with $C$. partellus; $\mathrm{SA}+\mathrm{IN}=$ treatment with $\mathrm{JA}$ and infested with C. partellus; $\mathrm{IN}=C$. partellus-infested plants; $\mathrm{UT}=$ untreated control plants 


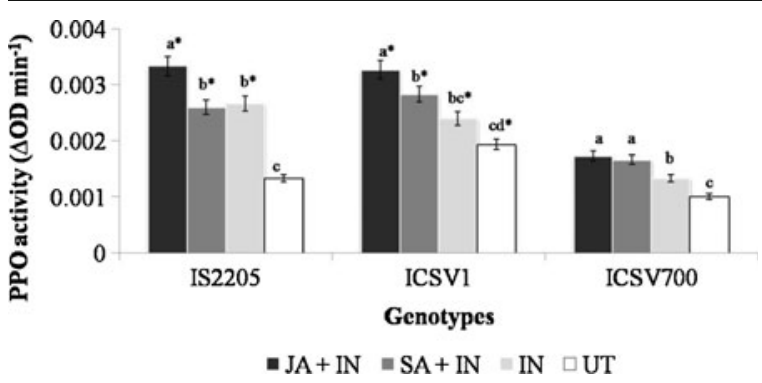

Fig. 2 Polyphenol oxidase (PPO) activity ( $\triangle \mathrm{OD} \mathrm{min}^{-1}$ ) of sorghum genotypes after Chilo partellus infestation and jasmonic acid (JA) and salicylic acid (SA) application. Within a genotype, bars (mean $\pm \mathrm{SD}$ ) of the same color with a common letter do not differ statistically at $P \leq 0.05 . \mathrm{JA}+\mathrm{IN}=$ treatment with $\mathrm{JA}$ and infested with $C$. partellus; $\mathrm{SA}+\mathrm{IN}=$ treatment with $\mathrm{SA}$ and infested with $C$. partellus; $\mathrm{IN}=C$. partellus-infested plants; $\mathrm{UT}=$ untreated control plants

treated plants. However, SA + IN, IN treated and untreated control plants of ICSV1 showed significantly greater SOD activity than those of IS2205 and ICSV 700 .

CAT activity The SA + IN treated plants showed greater CAT activity among all the treatments in the tested sorghum genotypes, followed by JA + IN treated and insect-infested plants. However, the least activity was observed in the untreated control plants in all the genotypes (Fig. 4). Among the genotypes, CAT activity was greater in ICSV700 than the other genotypes (IS2205 and ICSV1) in JA- and SA-treated plants.

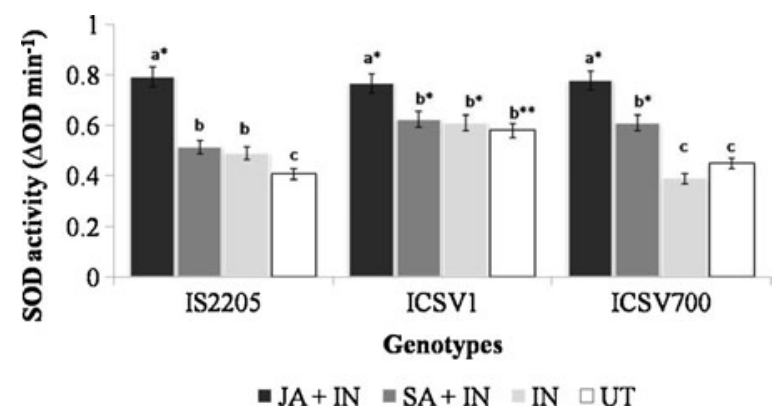

Fig. 3 Superoxide dismutase (SOD) activity $\left(\Delta \mathrm{OD} \mathrm{min}^{-1}\right)$ of sorghum genotypes after Chilo partellus infestation and jasmonic acid (JA) and salicylic acid (SA) application. Within a genotype, bars (mean $\pm \mathrm{SD}$ ) of the same color with the same letter do not differ statistically at $P \leq 0.05 . \mathrm{JA}+\mathrm{IN}=$ treatment with JA and infested with $C$. partellus; $\mathrm{SA}+\mathrm{IN}=$ treatment with $\mathrm{SA}$ and infested with $C$. partellus; $\mathrm{IN}=C$. partellus-infested plants; UT $=$ untreated control plants

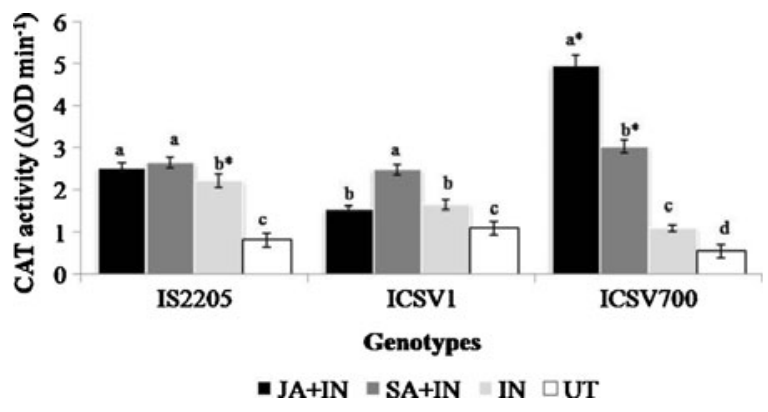

Fig. 4 Catalase activity ( $\triangle \mathrm{OD} \mathrm{min}^{-1}$ ) of sorghum genotypes after Chilo partellus infestation and jasmonic acid (JA) and salicylic acid (SA) application. Within a genotype, bars (mean $\pm \mathrm{SD}$ ) of the same color with the same letter do not differ statistically at $P \leq 0.05$. JA $+\mathrm{IN}=$ treatment with JA and infested with $C$. partellus; $\mathrm{SA}+\mathrm{IN}=$ treatment with $\mathrm{SA}$ and infested with C. partellus; $\mathrm{IN}=C$. partellus-infested plants; $\mathrm{UT}=$ untreated control plants

Insect-infested plants of IS2205 had significantly greater CAT activity than those of ICSV1 and ICSV700. Untreated control plants of ICSV1 had greater CAT activity than those of IS2205 and ICSV700.

Total phenols Significant differences were found between the treated and untreated plants in the sorghum genotypes (Fig. 5). Among the treatments, JA $+\mathrm{IN}$, $\mathrm{SA}+\mathrm{IN}$ treated, and insect-infested plants showed increased levels of total phenols as compared with untreated plants in all the genotypes. However, overall, the induction was significantly greater by JA-treated and insect-infested plants than by the SA + IN treated ones across the genotypes. Among the tested genotypes, IS2205 plants showed significantly greater phenolic content in all the treatments as compared with the corresponding treatments of ICSV1 and ICSV700.

$\mathrm{H}_{2} \mathrm{O}_{2}$ content Plants treated with JA + IN and IN with insects showed greater levels of $\mathrm{H}_{2} \mathrm{O}_{2}$ as compared with the untreated plants in all the tested genotypes; however, JA + IN- and SA + IN-treated plants had more $\mathrm{H}_{2} \mathrm{O}_{2}$ than insect-infested and untreated control plants (Fig. 6). Across the genotypes, IS2205 and ICSV1 plants treated with JA + IN and SA + IN and infested with insects had greater levels of $\mathrm{H}_{2} \mathrm{O}_{2}$ than those of corresponding treatments of ICSV700. Untreated plants did not show any significant difference in $\mathrm{H}_{2} \mathrm{O}_{2}$ levels across the genotypes. 


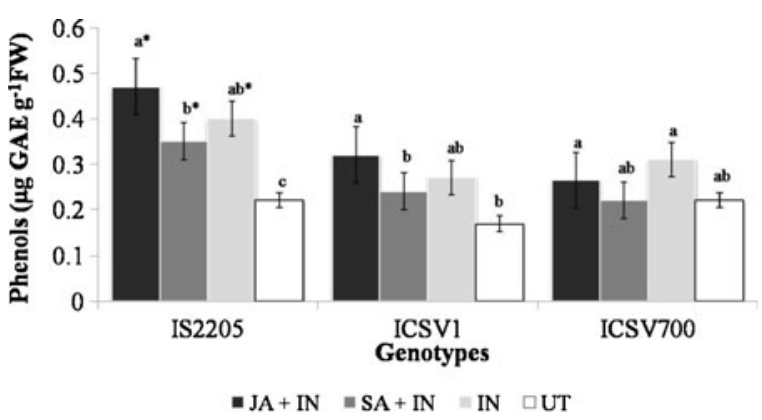

Fig. 5 Total phenols ( $\mu \mathrm{g}$ GAE $\mathrm{g}^{-1} \mathrm{FW}$ ) of sorghum genotypes after Chilo partellus infestation and jasmonic acid (JA) and salicylic acid (SA) application. Within a genotype, bars (mean $\pm \mathrm{SD}$ ) of the same color with a common letter do not differ statistically at $P \leq 0.05$. JA $+\mathrm{IN}=$ treatment with $\mathrm{JA}$ and infested with $C$. partellus; $\mathrm{SA}+\mathrm{IN}=$ treatment with $\mathrm{SA}$ and infested with C. partellus; $\mathrm{IN}=C$. partellus-infested plants; $\mathrm{UT}=$ untreated control plants; $\mathrm{GAE}=$ gallic acid equivalents; $\mathrm{FW}=$ fresh weight

MDA content Insect-infested plants showed significantly greater MDA content than the plants treated with JA + IN, SA + IN, and untreated plants in all the tested genotypes, followed by the plants treated with SA and JA (Fig. 7). Across the genotypes, IS2205 exhibited greater levels of MDA in all the treatments as compared with that of ISV1 and ICSV700.

Protein content Protein content increased in plants treated with JA followed by infestation with C. partellus in all the sorghum genotypes as compared with the plants treated with SA + IN and infested and untreated control plants (Fig. 8). Among the genotypes, ICSV700

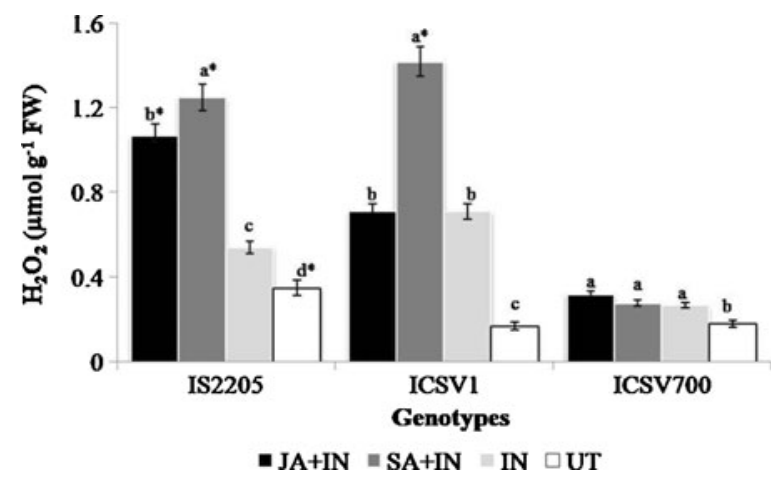

Fig. $6 \mathrm{H}_{2} \mathrm{O}_{2}$ content $\left(\mu \mathrm{mol} \mathrm{g}{ }^{-1} \mathrm{FW}\right)$ of sorghum genotypes after Chilo partellus infestation and jasmonic acid (JA) and salicylic acid (SA) application. Within a genotype, bars (mean $\pm \mathrm{SD}$ ) of the same color with the same letter do not differ statistically at $P$ $\leq 0.05 . \mathrm{JA}+\mathrm{IN}=$ treatment with $\mathrm{JA}$ and infested with $C$. partellus; $\mathrm{SA}+\mathrm{IN}=$ treatment with $\mathrm{SA}$ and infested with $C$. partellus; $\mathrm{IN}=C$. partellus-infested plants; $\mathrm{UT}=$ untreated control plants; $\mathrm{FW}=$ fresh weight

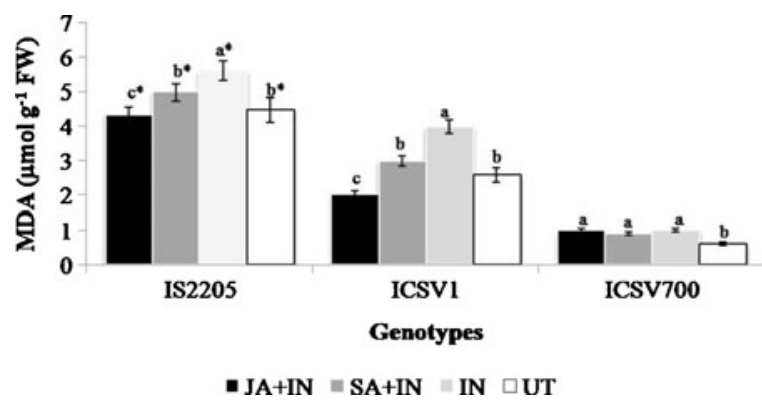

Fig. 7 Malondialdehyde (MDA) content $\left(\mu \mathrm{mol} \mathrm{g} \mathrm{g}^{-1} \mathrm{FW}\right)$ of sorghum genotypes after Chilo partellus infestation and jasmonic acid (JA) and salicylic acid (SA) application. Within a genotype, bars (mean $\pm \mathrm{SD}$ ) of the same color with the same letter do not differ statistically at $P \leq 0.05 . \mathrm{JA}+\mathrm{IN}=$ treatment with JA and infested with $C$. partellus; $\mathrm{SA}+\mathrm{IN}=$ treatment with SA and infested with $C$. partellus; $\mathrm{IN}=C$. partellus-infested plants; UT $=$ untreated control plants; $\mathrm{FW}=$ fresh weight

and ICSV1 showed significantly higher protein content in plants pre-treated with JA and SA followed by insect infestation, and the insect-infested plants than did IS2205.

\section{Discussion}

The ability of plants to recognize and respond defensively to insect attack constitutes a form of immunity that reduces herbivore survival, reproductive capacity, or preference for a plant. This is termed as "induced resistance". JA and SA are the important phytohormones involved in modulating plant defense against

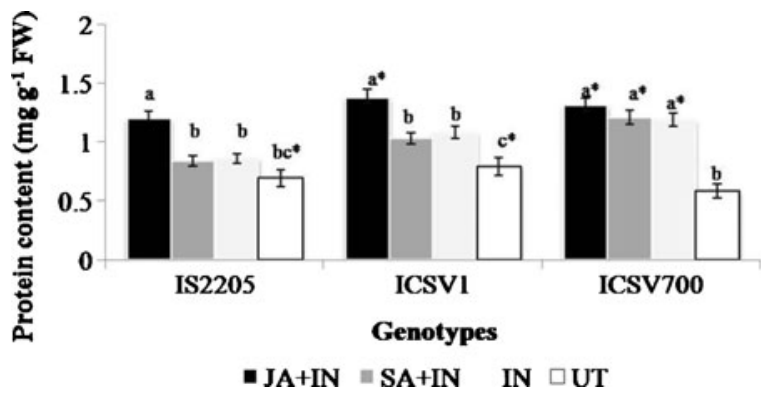

Fig. 8 Protein content $\left(\mathrm{mg} \mathrm{g}^{-1} \mathrm{FW}\right)$ of sorghum genotypes after Chilo partellus infestation and jasmonic acid (JA) and salicylic acid (SA) application. Within a genotype, bars (mean \pm SD) of the same color with a common letter do not differ statistically at $P \leq 0.05 . \mathrm{JA}+\mathrm{IN}=$ treatment with $\mathrm{JA}$ and infested with $C$. partellus; $\mathrm{SA}+\mathrm{IN}=$ treatment with $\mathrm{SA}$ and infested with $C$. partellus; IN $=C$. partellus-infested plants; $\mathrm{UT}=$ untreated control plants; $\mathrm{FW}=$ fresh weight 
insect herbivory by mediating octadecanoid and phenylpropanoid pathways, respectively (Scott et al. 2010; Shivaji et al. 2010). Exogenous application of JA and SA has been reported to enhance plant resistance against herbivores (Peng et al. 2004; Zhao et al. 2009). Methyl jasmonate (MeJA) or cis-jasmone is a volatile derivative of JA and acts as a defense-inducing agent in plants against attacking herbivores (Bruinsma et al. 2009). The earlier and immediate response of plants to insect infestation results in the induced expression of plant metabolites and defensive enzymes. Induced resistance in plants is considered as a desirable crop protection strategy with relatively benign environmental impacts, as it allows plants to be phenotypically plastic against different stresses. In this study we examined the defensive biochemical response of three sorghum genotypes to feeding by $C$. partellus and JA and SA treatments.

Our results revealed that pretreatment with JA and SA, followed by infestation with C. partellus, resulted in greater POD activity in sorghum. However, a stronger response was observed in IS2205 plants treated with JA and infested with insects than those treated with SA and infested with insects. This could be attributed to the higher accumulation of JA in plants infested with insects and because of the application of JA, and the strong ability of the IS2205 genotype to withstand the biotic stress. However, the lower POD activity in $\mathrm{SA}+\mathrm{IN}$ plants than that of JA + IN- and insectinfested plants could be because of the cross talk between JA and SA (Cipollini et al. 2004; Koornneef \& Pieterse 2008). Higher levels of POD activity in response to JA and SA application and/or insect attack will defend plants from the insects, pathogens and other stresses through cell lignifications, wound healing, and the production of secondary metabolites (Heng-Moss et al. 2004; Rangasamy et al. 2009). Our results correlate with several earlier findings, where JA and insect infestation induced higher levels of POD and imparted resistance in plants against insect herbivory (Shivaji et al. 2010; War et al. 2011a, 2012).

Different genotypes of sorghum showed differential induction of PPO in response to JA, SA and insect infestation. This might be due to the difference in sensitive up-regulation response of genotypes to the biotic stress. The PPO plays an important role in plant defense against insect herbivory as an antinutritional enzyme, and reduces the food quality (Bhonwong et al. 2009; War et al. 2012). The quinines formed from the oxidation of phenols interact with the nucleophilic side chain of amino acids and cause protein cross-linking and, thereby, reducing their availability to insect pests (Bhonwong et al. 2009; Zhang et al. 2008). PPO is also involved in the melanin formation that increases the cell wall resistance to insects and pathogens (Zhao et al. 2009).

Plants treated with JA and infested with insects showed significantly greater levels of SOD activity. The differential activity of SOD might be due to the difference in plant response across the treatments. SOD is involved in the removal of highly toxic and unstable ROS (Raychaudhuri \& Deng 2000). Saruhan et al. (2012) reported the induction of SOD activity by SA and its relation to the reduced oxidative damage. It has been further reported that Helicoverpa zea infestation produced higher levels of SOD activity in tomato and soybean ( $\mathrm{Bi} \&$ Felton 1995; Felton et al. 1994). It reduces the toxicity of ROS by converting them into less toxic and more stable components such as $\mathrm{H}_{2} \mathrm{O}_{2}$ and water (Heidari 2009; Khattab \& Khattab 2005). Higher activity of CAT in plants plays a leading role in cell wall resistance, besides signaling the expression of various plant defensive genes (Chen et al. 1993).

Phenols are the important plant secondary metabolites involved in defense against biotic and abiotic stresses. Total phenolic content was greater in plants treated with JA and infested with insect pests. Increase in total phenols is a common reaction of plants to herbivory (Karban \& Baldwin 1997). Phenolic compounds directly affect the insect growth and development (Green et al. 2003; War et al. 2013). There are several reports showing the induction of phenols in plants in response to insect attack (He et al. 2011; Sharma et al. 2009; War et al. 2011a,b).

ROS production in plants in response to the oxidative stress by biotic and abiotic factors is common in plants (He et al. 2011; War et al. 2011a,b, 2012). ROS mediate various signaling pathways involved in plant defense against stresses (Maffei et al. 2007). Among all the ROS, $\mathrm{H}_{2} \mathrm{O}_{2}$ is regarded as the most important as it is highly stable and more freely diffusible than all other ROS. It mediates the signal transduction pathways which lead to the expression of defense genes and thereby production of various defensive proteins in 
plants against insect herbivores (Maffei et al. 2007). In addition, $\mathrm{H}_{2} \mathrm{O}_{2}$ has been found to have direct toxicity against insects (Howe \& Jander 2008; Maffei et al. 2007). It also defends plants against subsequent insect and pathogen invasion (Maffei et al. 2007). JA and SA treatments followed by insect infestation showed greater $\mathrm{H}_{2} \mathrm{O}_{2}$ content in all the treatments. Our results correlate with earlier reports, where increase in the levels of $\mathrm{H}_{2} \mathrm{O}_{2}$ in plants after herbivore feeding and treatment with JA and SA has been observed (Walling 2000; War et al. 2011a,b).

Plants infested with insects showed higher amounts of MDA in all the sorghum genotypes. The induction was greater in the IS2205 genotype than in ICSV1 and ICSV700. This might be attributed to the severe oxidative stress due to wounding by insects. It has been suggested that MDA levels accumulate in plants after herbivore attack and assist in the synthesis of more complex defense compounds and activate antioxidative enzymes (Gechev et al. 2002; War et al. 2011a,b; Zhang et al. 2008). In addition, the emissions of green leaf volatiles, which are involved in indirect plant defense, are induced by lipid peroxidation after herbivore damage (Arimura et al. 2009). Our results are in line with earlier reports, where MDA levels were induced by insect damage (Huang et al. 2007; War et al. 2011a,b; Zhang et al. 2008).

In addition to secondary metabolites, which have been traditionally perceived as the major components of chemical defense strategies that regulate host plant utilization by insects (Sharma et al. 2009; War et al. 2012, 2013), proteins are also an important contributor to the plant's chemical defense mechanism. Proteins are a major and the most common limiting nutrient for insect growth. These compounds can alter the physiology of herbivores by reducing their growth rate, adult size, and survival probability (Harvey et al. 2003). There was a significant increase in protein content in all the genotypes on various treatments. However, JA induced significantly greater protein content in plants than the rest of the treatments. Increase in protein concentration might be endorsed to increased antioxidative enzyme activities after JA application and insect infestation. When under stress, plants produced various defense-related enzymes and other protein-based defensive compounds, thereby increasing the overall protein concentration (Chen et al. 2009; Lawrence \& Koundal 2002; War et al. 2011a,b, 2012). There are several reports showing the elevation of protein concentration in response to insect attack and JA application (Chen et al. 2009; He et al. 2011; War et al. 2011a, 2012).

\section{Conclusions}

The sorghum genotypes responded differentially to the infestation by $C$. partellus and treatment with JA and SA in terms of the defensive enzyme activities such as POD, PPO, SOD, CAT and the total amounts of phenols, $\mathrm{H}_{2} \mathrm{O}_{2}$, and MDA. Since these enzymes and other defensive components are responsible for the plant defense against biotic and abiotic stresses, sorghum genotypes with higher activity of these enzymes and other defensive components could be more resistant than the genotypes with low induced levels of these components. Alteration in digestibility and palatability of plant tissues by the induced compounds in response to insect attack affect insect growth and development adversely. The induced resistance could play an important role in pest management and defense mechanism against insect pests.

A detailed understanding of plant immunity to arthropod herbivores will provide new insights into basic mechanisms of chemical communication and plantanimal co-evolution and may also facilitate new approaches to crop protection and improvement.

\section{References}

Arimura, G., Matsui, K., \& Takabayashi, J. (2009). Chemical and molecular ecology of herbivore-induced plant volatiles: proximate factors and their ultimate functions. Plant and Cell Physiology, 50, 911-923.

Barbehenn, R., Dukatz, C., Holt, C., Reese, A., Martiskainen, O., Salminenm, J. P., et al. (2010). Feeding on poplar leaves by caterpillars potentiates foliar peroxidase action in their guts and increases plant resistance. Oecologia, 164, 993-1004.

Beauchamp, C., \& Fridovich, I. (1971). Superoxide dismutase: improved assay and an assay applicable to acrylamide gels. Annals of Biochemistry, 44, 276-287.

Bhonwong, A., Stout, M. J., Attajarusit, J., \& Tantasawat, P. (2009). Defensive role of tomato polyphenol oxidase against cotton bollworm (Helicoverpa armigera) and beet armyworm (Spodoptera exigua). Journal of Chemical Ecology, 35, 28-38.

Bi, J., \& Felton, G. W. (1995). Foliar oxidative stress and insect herbivory: primary compounds, secondary metabolites, and reactive oxygen species as components of induced resistance. Journal of Chemical Ecology, 1, 1511-1530. 
Bruinsma, M., Posthumus, M., Mumm, R., Mueller, M. J., van Loon, J. J. A., \& Dicke, M. (2009). Jasmonic acid-induced volatiles of Brassica oleracea attract parasitoids: effects of time and dose, and comparison with induction by herbivores. Journal of Experimental Botany, 60, 2575-2587.

Carmak, I., \& Horst, J. H. (1991). Effects of aluminium on lipid peroxidation, superoxide dismutase, catalase and peroxidase activities in root tips of soybean (Glycine max). Physiologia Plantarum, 83, 463-468.

Chen, Y., Ni, X., \& Buntin, G. D. (2009). Physiological, nutritional and biochemical bases of corn resistance to foliagefeeding fall armyworm. Journal of Chemical Ecology, 35, 297-306.

Chen, Z., Silva, H., \& Klessig, D. F. (1993). Active oxygen species in the induction of plant systemic acquired resistance by salicylic acid. Science, 262, 1883-1886.

Cipollini, D., Enright, S., Traw, M. B., \& Bergelson, J. (2004). Salicylic acid inhibits jasmonic acid-induced resistance of Arabidopsis thaliana to Spodoptera exigua. Molecular Ecology, 13, 1643-1653.

Felton, G. W., Bi, J., Summers, C. B., Mueller, A. J., \& Duffey, S. S. (1994). Potential role of lipoxygenases in defense against insect herbivory. Journal of Chemical Ecology, 20, 651-666.

Gechev, T., Gadjev, I., Van Breusegem, F., Inze, D., Dukiandjiev, S., Toneva, V., et al. (2002). Hydrogen peroxide protects tobacco from oxidative stress by inducing a set of antioxidant enzymes. Cellular and Molecular Life Sciences, 59, 708-714.

Green, P. W. C., Stevenson, P. C., Simmonds, M. S. J., \& Sharma, H. C. (2003). Phenolic compounds on the pod surface of pigeonpea, Cajanus cajan, mediate feeding behavior of larvae of Helicoverpa armigera. Journal of Chemical Ecology, 29, 811-821.

Harvey, J. A., Van Dam, N. M., \& Gols, R. (2003). Interactions over four trophic levels: foodplant quality affects development of a hyperparasitoid as mediated through a herbivore and its primary parasitoid. Journal of Animal Ecology, 72, 520-531.

He, J., Chen, F., Chen, S., Lv, G., Deng, Y., Fang, Z., et al. (2011). Chrysanthemum leaf epidermal surface morphology and antioxidant and defense enzyme activity in response to aphid infestation. Journal of Plant Physiology, 168, 687-693.

Heidari, M. (2009). Antioxidant activity and osmolyte concentration of sorghum (Sorghum bicolor) and wheat (Triticum aestivum) genotypes under salinity stress. Asian Journal of Plant Sciences, 8, 240-244.

Heng-Moss, T. M., Sarath, G., Baxendale, F., Novak, D., Bose, S., $\mathrm{Ni}$, X., et al. (2004). Characterization of oxidative enzyme changes in buffalograsses challenged by Blissus occiduus. Journal of Economic Entomology, 97, 1086-1095.

Howe, G. A., \& Jander, G. (2008). Plant immunity to herbivores. Annual Review of Plant Biology, 59, 41-66.

Huang, W., Zhikuan, J., \& Qingfang, H. (2007). Effects of herbivore stress by Aphis medicaginis Koch on the malondialdehyde contents and activities of protective enzymes in different alfalfa varieties. Acta Ecologica Sinica, 27, 2177-2183.

ICRISAT. (1992). Medium term plan 1992. Patancheru: International Crops Research Institute for the Semi-Arid Tropics (ICRISAT).
Karban, R., \& Baldwin, I. T. (1997). Induced responses to herbivory. Chicago: Chicago University Press.

Kawazu, K., Mochizuki, A., Sato, Y., Sugeno, W., Murata, M., Seo, S., et al. (2012). Different expression profiles of jasmonic acid and salicylic acid inducible genes in the tomato plant against herbivores with various feeding modes. Arthopod-Plant Interactions, 6, 221-230.

Khattab, H., \& Khattab, M. (2005). Responses of eucalypt trees to the insect feeding gall-forming psyllid. International Journal of Agricultural Biology, 7, 979-984.

Koornneef, A., \& Pieterse, C. M. J. (2008). Cross talk in defense signaling. Plant Physiology, 146, 839-844.

Lawrence, P. K., \& Koundal, K. R. (2002). Plant protease inhibitors in control of phytophagous insects. Electronic Journal of Biotechnology, 5, 93-109.

Lowry, O. H., Rosebrough, N. I., Farr, A. L., \& Randall, R. J. (1951). Protein measurement with the Folin phenol reagent. Journal of Biological Chemistry, 193, 265-275.

Maffei, M. E., Mithofer, A., \& Boland, W. (2007). Insects feeding on plants: rapid signals and responses preceding the induction of phytochemical release. Phytochemistry, 68, 2946-2959.

Mayer, A. M., \& Harel, E. (1979). Polyphenol oxidases in plants. Phytochemistry, 18, 193-215.

Noreen, Z., \& Ashraf, M. (2009). Change in antioxidant enzymes and some key metabolites in some genetically diverse cultivars of radish (Raphanus sativus L.). Environmental and Experimental Botany, 67, 395-402.

Peng, J., Deng, X., Huang, J., Jia, S., Miao, X., \& Huang, Y. (2004). Role of salicylic acid in tomato defense against cotton bollworm, Helicoverpa armigera Hubner. Zeitschrift für Naturforschung, 59, 856-862.

Rangasamy, M., Rathinasabapathi, B., McAuslane, H. J., Cherry, R. H., \& Nagata, R. T. (2009). Oxidative response of St. Augustinegrasses to feeding of southern chinch bug, Blissus insularis Barber. Journal of Chemical Ecology, 35, 796-805.

Raychaudhuri, S., \& Deng, X. W. (2000). The role of superoxide dismutase in combating stress in higher plants. Botanical Review, 66, 89-98.

Saruhan, N., Saglam, A., \& Kadioglu, A. (2012). Salicylic acid pretreatment induces drought tolerance and delays leaf rolling by inducing antioxidant systems in maize genotypes. Acta Physiologiae Plantarum, 34, 97-106.

Scott, M. I., Thaler, S. J., \& Scott, G. F. (2010). Response of a generalist herbivore Trichoplusia ni to jasmonate-mediated induced defense in tomato. Journal of Chemical Ecology, 36, 490-499.

Shannon, L. M., Kay, E., \& Lew, J. Y. (1966). Peroxidase isozymes from horseradish roots. Isolation and physical properties. Journal of Biological Chemistry, 241, 21662172.

Sharma, H. C., Sujana, G., \& Rao, D. M. (2009). Morphological and chemical components of resistance to pod borer, Helicoverpa armigera in wild relatives of pigeonpea. Arthopod-Plant Interactions, 3, 151-161.

Sharma, H. C., Taneja, S. L., Kameswara Rao, N., \& Prasada Rao, K. E. (2003). Evaluation of sorghum germplasm for resistance to insect pests. Information Bulletin no. 63 . Andhra Pradesh: International Crops Research Institute for the Semi-Arid Tropics. 
Shivaji, R., Camas, A., Ankala, A., Engelberth, J., Tumlinson, J. H., Williams, W. P., et al. (2010). Plants on constant alert: elevated levels of jasmonic acid and jasmonate-induced transcripts in caterpillar-resistant maize. Journal of Chemical Ecology, 36, 179-191.

Taneja, S. L., \& Leuschner, K. (1985). Methods of rearing, infestation, and evaluation for Chilo partellus resistance in sorghum. In Proceedings of the International Sorghum Entomology Workshop (pp. 175-188) (1984, College Station, TX, USA).

Walling, L. L. (2000). The myriad plant responses to herbivores. Journal of Plant Growth Regulation, 19, 195-216.

War, A. R., Paulraj, M. G., Hussain, B., Buhroo, A. A., Ignacimuthu, S., \& Sharma, H. C. (2013). Effect of plant secondary metabolites on legume pod borer, Helicoverpa armigera. Journal of Pest Science. doi:10.1007/s10340-013-0485-y.

War, A. R., Paulraj, M. G., War, M. Y., \& Ignacimuthu, S. (2011a). Jasmonic acid-mediated induced resistance in groundnut (Arachis hypogaea L.) against Helicoverpa armigera (Hubner) (Lepidoptera: Noctuidae). Journal of Plant Growth Regulation, 30, 512-523.
War, A. R., Paulraj, M. G., War, M. Y., \& Ignacimuthu, S. (2011b). Role of salicylic acid in induction of plant defense system in chickpea (Cicer arietinum L.). Plant Signaling and Behavior, 6, 1787-1792.

War, A. R., Paulraj, M. G., War, M. Y., \& Ignacimuthu, S. (2012). Herbivore induced resistance in different groundnut germplasm lines to Asian armyworm, Spodoptera litura (Fab.) (Lepidoptera: Noctuidae). Acta Physiologiae Plantarum, 34, 343-352.

Zhang, S. Z., Hau, B. Z., \& Zhang, F. (2008). Induction of the activities of antioxidative enzymes and the levels of malondialdehyde in cucumber seedlings as a consequence of Bemisia tabaci (Hemiptera: Aleyrodidae) infestation. Arthopod-Plant Interactions, 2, 209-213.

Zhao, L. Y., Chen, J. L., Cheng, D. F., Sun, J. R., Liu, Y., \& Tian, Z. (2009). Biochemical and molecular characterizations of Sitobion avenae-induced wheat defense responses. Crop Protection, 28, 435-442.

Zieslin, N., \& Ben-Zaken, R. (1993). Peroxidase activity and presence of phenolic substances in peduncles of rose flowers. Plant Physiology and Biochemistry, 31, 333-339. 